\title{
LA POESÍA DE CORTE MÍSTICO DE LA PRINCESA TURCO-OTOMANA ADİLE SULTAN (1826-1899)
}

\author{
NESRİN KARAVAR \\ Universidad de Barcelona \\ nesrinkaravar3@hotmail.com \\ ORCID: 0000-0001-9225-9244
}

\section{RESUMEN}

En el presente artículo se analiza la poesía mística de Adile Sultan como símbolo y comunicación con sagrado. Se recoge la rica experiencia de esta poeta para aproximarnos desde su visión a las realidades espirituales que vivía mediante su única obra poética Divan. En su época la búsqueda de la palabra poética es el motivo de una conversión hacia el modelo humano de la naturaleza divina que debía hacerse sensible. Como todas las mujeres místicas de las diferentes religiones Adile Sultan también ejerció de manera intensa la mirada interior. También analizaremos su época y literatura femenina turca del siglo XIX y XX.

PALABRAS CLAVE: poesía, otomana, literatura, mística, Adile Sultan, mujer, sufismo.

\section{THE MYSTICAL POETRY OF THE TURKISH-OTTOMAN PRINCESS ADILE SULTAN (1826-1899)}

\section{ABSTRACT}

This article analyzes the mystical poetry of Adile Sultan as a symbol and communication with God. The rich experience of this poet is collected to bring us closer from her vision to the spiritual realities she lived through her poetic work Divan. In her time, poem was the reason for a conversion towards the human model of divine nature that had to be made more sensitive. Like all mystical women of different religions, Adile Sultan also exercised her inner gaze intensely. We will also analyze her life story, her time and Turkish female literature of the $19^{\text {th }}$ and $20^{\text {th }}$ Century.

KEYWORDS: poem, Ottoman, literature, mystic, Adile Sultan, woman, Sufism.

\section{INTRODUCCIÓN: VIDA DE ADILE SULTAN}

Adile Sultan nació en 1825 en Estambul. Era hija del Sultan Mahmut II (1785-1839). En los archivos del palacio Topkapı su nacimiento está registrado así:

Cuando las fechas mostraban 23 de mayo de 1826 una habitación del palacio con cuatro sofas adornados con blancas almohadas. En ocho ventanas de la habitación y en su puerta están colgadas cortinas azules. En la esquina está el cuarto amarillo adornado con almohadas, dos minders rosados llenos de algodon y encima están dieciseis almohadas más. Esta habitación esta preparada para la niña que nacerá en el palacio del Sultán 
Mahmud II. La madre es Zernigar Kadınefendi. La embarazada Zernigar Kadınefendi, en 1826 en mayo, el día veinte tres nacerá una niña y su nombre será Adile Sultan. (Özdemir 2000: 12)

Los gastos de su nacimiento también están registrados en los archivos de palacio Topkap1:

Con motivo de su nacimiento se donaron 25.800 Dinares a los pobres. En el cuello de la pequeña Adile lucía un collar de diamantes y esmeraldas con la palabra Mashallah (palabra que, según la costumbre, protege del mal de ojo). (Özdemir 2000: 12)

A los cuatro años perdió a su madre y a los 13 años a su padre. La crió una señora del harén, Nevfidan Kadın a la que dedica los siguientes versos:

Después Nevfidan Kadın fue

Como una verdadera madre para mí

No ha dejado que nadie limpiase mis lágrimas

No he notado nunca que no tenía madre. (Sultan 1890: 83)

En 1845, a los 20 años, se enamoró y contrajo matrimonio con un almirante de las fuerzas navales otomanas. Su boda, que duró siete días, figura como la boda más importante y llamativa del siglo XIX. Tras la boda, vivió una vida lujosa, como todas las mujeres de la corte. Vida por la que tenía debilidad su marido. Siempre siguió enamorada de él, tal y como se desprende de estos versos:

En este mundo había un señor llamado Muhammed Ali Pasha

Que Dios le haga feliz en el mundo eterno

Era muy feliz con él

Me quería mucho

$[\ldots]$

Adile llora por un marido como él

Era Muhammed Ali Pasha

Que Dios le muestre su cara en el otro mundo. (Sultan 1890: 67)

Muchas veces se vestía de calle y se mezclaba con la gente, llevaba a otras mujeres con ella para que conocieran la vida y la gente de Estambul. Su hermano, el Sultán Abdulmecid (1823-1861), apoyaba los cambios e innovaciones del Imperio Otomano y por eso apoyaba a su hermana, pero una parte de la corte no veía bien estos cambios y, aunque no se atrevían a criticarla en voz alta, no apoyaban la actitud libre de Adile Sultan ni su modo de enseñar a las mujeres a salir a conocer la ciudad.

Tuvo cuatro hijos, pero su marido y sus hijos murieron. Después de estas muertes, se retiró del mundo y se refugió en la educación de las mujeres y la literatura, al mismo tiempo que buscó una vida más espiritual. Se apropió de la escritura para hablar de sí misma y de Dios, pues Dios fue a quien encontró en 
su palacio: «Mira a través de los ojos del corazón al mundo / Lee el misterio a través de los poemas» (1890: 136).

Como todas las mujeres místicas de las diferentes religiones Adile Sultan también ejerció de manera intensa la mirada interior.

\section{ÉPOCA DE LAS REFORMAS (1839)}

El cambio del peso de la literatura tradicional y de la corte realmente empezó en 1839 con la época de las Reformas (Tanzimat, en turco) con las traducciones de la literatura europea y con apoyo del padre de Adile Sultan, Mahmud II. A partir de este período de Reformas los periodistas, los militares, los literatos laicos y seculares también salieron a la escena de la literatura. Pero esta nueva clase en un sentido también siguió el sistema antiguo: Estar bajo la protección del palacio de Bab-ı Ali (Sublime Puerta), el centro de la burocracia del gobierno. Así la relación estrecha entre literatura y política siguió igual, cambiando solo el perfil de los escritores y poetas.

Como afirma la socióloga turca Nilüfer Göle este proceso de las reformas es una proyección del modelo cultural occidental:

Estos designios impregnados de occidentalismo triunfante tienen su origen en el
pensamiento humanista del siglo XIX y hacen eco al proceso de modernización impulsado
por la elite reformista turca desde el período de las reformas llamado de las Tanzimat (1839-
1876) y está animado por las ideas de los filósofos del siglo XVIII, puntal de la civilización
industrial. (Göle 1991: 7)

Y sigue: «La historia de Turquía se puede ver como un esfuerzo voluntariamente realizado para lanzar un puente cultural hacia la orilla occidental» (1991: 8).

El primer signo inequívoco de la occidentalización, la imprenta, entró a las tierras del imperio el año 1727, de mano de İbrahim Müteferrika de origen rumano (1674-1745) con permiso del Súltan y con el fin erudito principal de publicar en turco-otomano solo los libros dedicados a la historia, medicina y diccionarios. Su entrada no desarrolló las publicaciones literarias turcas aunque podrían haber aprovechado a hacer con la entrada de la imprenta un boom de la literatura islámica de la época. La primera traducción publicada el 1728 fue el diccionario Şihahül Arabiyye del linguista de origen turco al-Jawhari (940-1002) y luego el libro La Alqumia de la Felicidad del filósofo irani Imam al-Ghazali (1058-1111). A partir del año 1803 el Sultán Mahmud II, padre de Adile Sultan dio permiso para publicar libros de teología islámica. La experiencia otomana refleja ese debate permanente como se puede ver en la historia de la imprenta 
otomana entre progresistas y conservadores que todavía sigue hoy en día entre dos grupos en la República de Turquía.

Con las reformas en el ámbito de la literatura el gobierno del palacio (Bab-ı Ali) fundó una academia de traducción llamada Encümen-i Dâniş. El 1786 el griego-otomano Todoraki Efendi tradujo del francés la Historia Universal del historiador Louis-Philippe Comte de Segur (1753-1830), considerado como uno de los primeros libros europeos traducidos al otomano. Este movimiento de las reformas en la literatura estaba influenciado por el romanticismo francés.

Como podemos ver en unos poemas de Adile Sultan, dentro de las fronteras del Imperio, las expresiones como «pueblo», «nación», «el derecho del pueblo» empezaron a aparecer recién después de las Reformas: «Muhammad Ali Pasha fue justo con los políticos / con los militares, intelectuales y con todo el pueblo» (1890: 83).

En la literatura otomana del siglo XIX, la nueva literatura reformista, se realizaron enciclopedias, periódicos, diccionarios, novelas y obras de teatro por parte de estos nuevos intelectuales. El palacio tradicional lentamente empezó a perder su peso y aparecieron los cambios en la sociedad y entre los miembros del palacio como Adile Sultan. La cuestión de la mujer está en el corazón mismo del debate: en un país musulmán, el papel de la mujer en la sociedad define los retos mismos de la occidentalización y como vemos en la vida de Adile o de las otras mujeres de su época como Zeynep Hanım (m. 1923), la primera escritora de viajes. En su libro A Turkish Woman's European Impressions escribió cuestionando de manera general la cultura y la civilización de un imperio islámico:

We Turkish women read a great deal of foreign literature, and this does not tend to make us any more satisfied with our lot. Amongst my favorite English books were Beatrice Harraden's Ships that Pass in the Night,1 passage of which I know by heart, and Lady Mary Montagu's Letters. Over and over again, and always with fresh interest, I read those charming and clever letters. Although they are the letters of another century, there is nothing in them to shock or surprise a Turkish woman of to-day in their criticism of our life. It is curious to notice, when reading Lady Mary's Letters, how little the Turkey of today differs from the Turkey of her time; only, Turkey, the child that Lady Mary knew, has grown into a big person. (Zeynep Hanım 1913: 38)

$[\ldots]$

Unlike our grandmothers, who accepted without criticism their "written fate," we analyzed our life, and discovered nothing but injustice and cruel, unnecessary sorrow. Resignation and culture cannot go together. Resignation has been the ruin of our country. There never would have been all this suffering, this perpetual injustice, but for resignation; and resignation was no longer possible for us, for our Faith was tottering. (Zeynep Hanım 1913: 41)

Los movimientos de la nueva literatura otomana turca comenzaron a desarrollarse en este ámbito revolucionario. Aunque querían reformas, las 
querían sin rechazar toda la literatura tradicional, junto con la historia, geografía y con la vida real de la sociedad otomana sin imitar la sociedad europea. Como por ejemplo afirma uno de los novelistas (de ciudad) más importantes Ahmet Hamdi Tanpinar (1901-1962) hasta que sus compañeros imitaban en sus poemas el viento, la lluvia, el gris de los Países Bajos cuando escribían los poemas desde Estambul. Clotilde Cerdá (Esmeralda Cervantes, 1861-1926) la profesora de arpa del harén del palacio Yıldız en Estambul entre los años 1890-1893 escribe en el Diario de Tenerife en 1904 su opinión sobre el cambio de las señoras musulmanas:

Cuando hoy día muchas, la mayor parte de las señoras musulmanas hablen francés, inglés o alemán. Esta misma instrucción que reciben les hace olvidar su educación religiosa y las costumbres nacionales, queriendo vivir a la manera europea; de esas señoras no se puede tener una idea cierta de los principios de la vida musulmana, pues no la conocen ellas mismas. (Cervantes 1904: 2)

\section{LITERATURA FEMENINA TURCA DEL SIGLO XIX Y XX}

El lugar de la mujer en la sociedad comenzó a ser debatido desde las primeras tentativas de modernización del período de las Tanzimat (reformas). La mejor información sobre mujer y literatura en la sociedad turca otomana de esta época la podemos encontrar en el discurso de la arpista catalana Clotilde Cerdá (Esmeralda Cervantes). En su discurso en el Congreso de Chicago de 1893 en «Education and Literature of the Women of Turkey» explica la influencia de estas reformas en la vida de las mujeres:

I can safely testify that their instruction and development are not in the least inferior to the education of our own intelligent ladies. Several European authors have founded the erroneous idea they had about female education in the Orient, on totally wrong interpretations of the Koran, which, they pretend, condemns woman to remain in ignorance. (Cervantes 1893: 3)

Y sigue:

The Muslim woman's education has realized during the last fifteen years, a progress that is indeed marvelous. It was only needed to give a little help to the development of her mental faculties, in order to enable the Oriental woman to make herself worthy in so short a time for a place in this universal Congress either in person or by representation. As I have already said the Mahometan religion is not and obstacle to woman's development. The Koran which contains the basis of all liberal institutions and social duties, mutual assistance, equality before the law, respect towards the family, etc., says: "Woman's education must be equal to man's" (Koran 33: 35). (Cervantes 1893: 4)

En su discurso menciona a las escritoras más conocidas de la época como Fatma Aliye (1862-1936). La nueva imagen de la mujer se plasma de manera 
brillante en las novelas y en la vida misma de Fatma Aliye. Por ejemplo, su novela Udi (Instrumentista de laúd) en 1899 se tradujo al francés por Gustave Seon. En Udi una mujer joven da clases privadas de laúd para ganar su propio dinero para comprar su casa. Las protagonistas de Fatma Aliye siempre son mujeres independientes, unidas al pueblo con personalidad destacada y luchan contra el arquetipo de estilo «mujer necesitada de protección» y «mujer sensible». Su obra sobre las primeras mujeres de la época del Islam, Namdaran-ı Zenan-ı İslamiyan, es una de las primeras obras en los estudios de la historia de las feministas. En la feria del libro de Chicago (1893) incluyeron su biografía y sus novelas en The Woman's Library of The World's Fair:

Who wrote various works, among which 'The Muslim Women' is a classic book full of detail on the customs and habits of oriental women. She also has translated George Ohnet's Volonte. (Cervantes 1893: 4)

También menciona Clotilde Cerdá en su discurso otra escritora y filósofa Makboula Hanoum: «Her works are published daily in the Turkish journal, Terdjuman Hakikat» (Cervantes 1893: 4).

En su discurso histórico como poeta menciona solo a Leila Hanoum (1859-1936) no a Adile Sultan muy probablemente por su carácter de protectora de las mujeres débiles:

Daughter of the late Ismail Pasha is well known by her articles and her poetry which have been published in the Turkish papers. Is indeed to be regretted that her works have never been published in one volume. (Cervantes 1893: 4)

Sigue con otras más:

"Gulnar Hanoum is a remarkable philosophic writer."

"Muhrul Nessa Hanoum is still very young and of great promise. She has been known and much admired through the journals which have published her works."

"Zafer Hanoum, wife of Hilmi Effendi, is familiar with the French, Turkish, Greek, Arabic and Persian languages. She has written four books, one of which is a novel."

"Kamer Hanoum has written a book on Mohammedan religious precepts."

"Emine Semie Hanoum is the author of an arithmetic, which she has written for the benefit of the pauper asylum. I might still mention many other Turkish lady authors, but the too narrow limits of this study allow me to go no further." (Cervantes 1893: 4)

En este sentido, la viajera inglesa Lucy Garnett (1849-1934) informa sobre las niñas otomanas lo que sigue:

La cultura actual otomana hoy en día se perdió su identidad propia y solo esta imitando el Occidente. Han cambiado el método de educación. Al menos los colegios de niños tienen una enseñanza más europea. Hace treinta o cuarenta años a las niñas de clase alta se les 
enseñaba en su lengua materna a escribir poesía, cantar, bailar, tocar laúd o daf, memorizar los versículos del Corán y poemas de los poetas. (Garnett 2009: 521)

Hay que tener en cuenta que la educación religiosa y tradicional otomana de esta época no solo tenía desventajas, también les dio a estas nuevas intelectuales turcas una disciplina mental y espiritual como podemos observar particularmente en la poesía Adile Sultan y en las novelas de Fatma Aliye. A partir de Adile Sultan la mujer musulmana otomana, independientemente de su identidad colectiva, empieza a progresar en el desarrollo de estrategias de vida individual cuestionando las prohibiciones de acceso al mundo exterior $\mathrm{y}$, con ello, más avanza en la forja de su propia identidad y en la redefinición de las relaciones entre los hombres y las mujeres como en las reuniones mixtas literarias que organizaba Adile en su palacio.

\section{AdILE SUlTAN, CREADORA DE UN NUEVO GÉNERO OTOMANO: LA POESÍA MÍSTICA FEMENINA}

El idioma literario otomano tradicionalmente fue el persa. Adile empieza a utilizar en ocasiones palabras turcas en sus poemas. Fue el poeta del siglo XIII, Yunus Emre (m. 1321), originario de Anatolia Central, quién transformó su lengua materna, el turco, en vehículo de experiencia mística, con poemas más simples y fáciles de guardar en la memoria para los lectores turcos que los poemas escritos en persa, o con un otomano utilizando en ocasiones palabras persas y árabes. Las imágenes no proceden únicamente del legado tradicional, sino que se inspiran también en la vida cotidiana. A pesar de que Adile no logró el éxito literario que Leyla Hanım y Fitnat Hanım (1842-1911), dos poetisas reconocidas de su época, si fue la primera en enfrentarse a los prejuicios de la sociedad. Su obra literaria arroja luz sobre los incidentes en el palacio y la administración del Imperio Otomano. También compuso un poema sobre el presunto asesinato de su hermano menor, el Sultán Abdülaziz (1830-1876), que se conoce oficialmente como un suicidio:

\footnotetext{
Cómo no voy a sufrir por lo que ocurrió a mí Sultán

No se sabe lo que le pasó. Mataron al que fue la sombra de Dios

El fue al mundo eterno pero su dolor quedó en los corazones

Ocurrió un terremoto en palacio, dejó el mundo llorando. (1890: 65)

Otros versos como testigo de su época:

Cuando iban a entrar a la batalla con Rusia

Cuando vino el Principe Ménshikov. (1890: 88)
} 
Adile Sultan vive en el siglo XIX, período de grandes cambios en el Imperio Otomano. En este sistema nuevo las conductas de las mujeres serán diferentes, se organizará de manera que las mujeres puedan participar lentamente en la vida social. Cambios que también se notaron y empezaron en las casas señoriales de las costas del Bósforo en las que transcurre la vida de la poetisa, siendo ella una de las principales artífices del cambio en lo que respecta a la situación de la mujer, como leemos en las informaciones de Zeynep Hanım y Clotilde Cerdá (Esmeralda Cervantes).

Resulta, pues, que las mujeres musulmanas de un imperio islámico se oponen a encerrarse en una vida limitada al papel de esposa. Estas mujeres como Adile Sultan ponen de manifiesto que, tras la actitud de los hombres musulmanes que se refugian en el islam e imparten consejos a las mujeres, no se esconde la religión, sino los intereses del hombre musulmán. Siempre prohibiciones para las mujeres, porque está prohibido por la religión. Pero como vemos en Adile Sultan este cuestionamiento de las prohibiciones por parte de las mujeres de las elites no queda sin respuesta.

Adile Sultan es la primera otomana que publicó un libro de poesía mística y además publicó por primera vez los poemas de su antepasado Solimán el Magnífico, en 1890. Como a su padre y a los derviches sufís a ella también le interesaban la música y el arte, especialmente dentro del arte islámico la caligrafía como muestra en algunos de sus poemas:

Doy gracias a mi Sultán que no he tenido una vida difícil

Una vida como un papel amarillo de la caligrafía. (1890: 240)

Sus versos sobre música muestran su educación profunda en la música:

La música para los enamorados es una fuerza y es placer del corazón

La música para los creyentes es un deseo, es un mensajero. (1890: 107)

Quema con la composición de la Hicaz y de la composición Uşşak

Música es una batalla de la composición Acem y paz de Isfehan

Hace feliz el enamorado y cada día suyo se vuelve festivo

Música es para los oídos emborrachados de la Saba es una fiesta del corazón. (1890: 157)

Los escritos de Adile inauguraron un nuevo género femenino, el de la «poesía espiritual». Por tal motivo, no sólo es reconocida hoy como «la primera gran poeta mística en lengua otomana» y «como una de las mejores poetas de dicha lengua», gracias a su Divan, sino que, a la par de la de sus contemporáneas, su obra también ha sido valorada en tanto ofrece vías de renovación del lenguaje místico actual. Aunque Adile Sultan en la historia de la poesía mística del Islam no es la primera mujer, como señala la teóloga inglesa Margaret Smith (1884-1970): 
In the history of Islam, the woman saint made her appearance at a very early period, and in the evolution of the cult of saints by Muslims, the dignity of saintship was conferred on women as much as on men. As far as rank among the "friends of God" was concerned, there was complete equality between the sexes. It was the development of mysticism (Sufism) within Islam, which gave women their great opportunity to attain the rank of sainthood. (Smith 1928: 2)

La mayoría de sus poemas están dedicados a Dios, al Profeta, a los maestros espirituales y a los miembros de su familia, pero también escribió poemas con un tono de rebeldía como este: «Soy derviche y al mismo tiempo soy princesa / Viajo por el mundo del amor» (1890: 230).

La poesía de Adile posee una gran riqueza simbólica y alusiva. A través de la poesía ha intentado expresar su aventura espiritual, según la cual el universo se explica no solo a partir de lo meramente físico, sino también de lo espiritual. En la terminología del sufismo clásico, el viajero espiritual es denominado sâlik. Cuando le preguntaron al poeta sufí persa Mahmud Şebüsteri (1288-1320) sobre quién es un viajero, éste contestó así: «El que vuelve la cara hacia el Profeta. Quien viaje en sí mismo» (Şebüsteri 2011: 79). En el texto coránico existen varios ejemplos de viaje espiritual. Uno de ellos es el viaje realizado por Moisés bajo la guía de Hizır. Con todo, el viaje espiritual por antonomasia relatado en el Corán es el viaje nocturno del Profeta, que ha servido de modelo al sufismo clásico. Que los sufís del islam habían empleado antes de la ficción poética de un viaje de ultratumba como alegoría moral de la vida humana en su ascensión hasta Dios. En la poética de Adile esta noche esta explicada así:

Si quieres saber el secreto de este encuentro

Lee el versículo sobre su distancia de Ka'ba

El secreto está en su cara noble

Los amantes tienen este secreto. (1890: 39)

Tal vez en la literatura sufí el cuento más emblemático referido al viaje espiritual sea el Mantıku't-Tayr o El lenguaje de los pájaros de Ferîdüddin Attâr (1136-1221), protagonizado por un grupo de pájaros que simbolizan a las almas comprometidas en la búsqueda iniciática. Adile en unos de sus versos hace referencia a este viaje simbólico de Attâr: «El corazón es fuerte como la montaña de Qaf, mira el alma del pájaro Anka / Está buscando en la montaña de Qaf el pájaro Anka» (1890: 28).

El filósofo Henry Corbin (1903-1978), decía que nadie ha visto nunca el alma con los ojos con que normalmente vemos las cosas de este mundo. Con lo que ver y comprender el símbolo supone, en cierta medida, morir a la mirada materialista o, lo que es lo mismo, despertar de nuevo del olvido (Corbin 2000: 133). 
Según la filosofía corbiniana, el viaje espiritual al que hacen referencia los poetas sufíes, como el caso que aquí nos ocupa de Adile, es un acontecimiento que se repite de forma transhistórica y que tiene por objetivo la llamada «tierra de luz», que solo se ve con los ojos del corazón.

El viaje como metáfora de la búsqueda espiritual y apertura a lo que desconocemos, esa supra-realidad que está por encima de lo que consideramos real, es uno de los elementos más comunes del sufismo clásico. Afirma Adile al respecto: «¡Oh Dios! Ayúdame para pasar por el puente / facilítanos el viaje espiritual» (1890: 5).

O dice: «Adile, esfuérzate a entender repitiendo los bellos nombres de Dios / El viajero espiritual con éxtasis y danza tiene su felicidad» (1890: 205).

Las prácticas extatogénicas seguidas por los místicos para ir más allá de la coraza mental y alcanzar un estado de unión divina son diversos: ayunos, danzas, giros y distintas formas de auto hipnosis. También es común la utilización de fórmulas y jaculatorias repetidas hasta el anonadamiento.

Por otra parte, Gazali caracteriza la experiencia mística así:

The science of the sufis aims at detaching the heart from all that is not God, and at giving to it for sole occupation the meditation of the divine being. Theory being easier for me than practice, I read certain books until I understood all that can be learned by study and hearsay. Then I recognized that what pertains most exclusively to their method is just what no study can grasp, but only transport, ecstasy, and the transformation of the soul. How great, for example, is the difference between knowing the definitions of health of satiety, with their causes and conditions, and being healthy or filled. How different to know in what drunk-enness consists- as being a state occasioned by a vapor that rises from the stomach-and being drunk effectively. Without drunken man can knows the definition of drunkenness [...]. (Williams 1901-1902: 394)

Según los sabios y maestros del sufismo, en el momento del éxtasis el derviche alcanza un nivel más elevado, de percepción, abriéndose a una comprensión inmediata de la realidad, comúnmente denominada sexto sentido y estudiado por la psicología como un fenómeno inusual de la conciencia y la mente; en otras palabras, obtiene una mirada nueva que le permite ver lo que para el hombre común permanece siempre invisible u oculto (Uludağ 2004: 177-178).

La «tierra de luz», a la que aludíamos anteriormente, se expresa en la obra de Adile:

Eres belleza de la noche del universo

Tierra y cielo llenó con Tu luz

El amante se quemó con Tu amor

$[\ldots]$ 
¿Quién encuentra luz del oriente y del occidente?

Son los dueños de los corazones los que están cerca al faro de la luz. (1890:23)

Como ocurre con el resto de poetas espirituales islámicos, también Adile concibe la «tierra de luz» en el marco de la historia simbólica del exilio metafísico del ser humano y el retorno de éste a su fuente original, algo que constituye el motivo central de la mística de Adile, reflejada en los versos de la poesía.

La propia personalidad de Adile nos brinda un valioso ejemplo acerca del desarrollo y ensanchamiento espiritual como tal, desde el nivel inanimado de la vida hasta el nivel superior o divino, eso que los sabios sufíes denominan el ser humano perfecto que no es sino la máxima expresión del hombre total, quien ha actualizado todas sus potencialidades latentes y es espejo en el que Dios se mira. Adile fue prueba ella misma de un estado espiritual sublime, el de quien ha desarrollado en sí mismo la presencia plena de Dios. Una sensación común a muchas experiencias extáticas es encontrarse fuera del cuerpo, observándose desde lo alto, como si se flotara cerca del techo de una habitación y se hiciese la observación de ella a vista de pájaro. Muchos investigadores contemporáneos de tales fenómenos extáticos han nombrado el cuerpo en el que el sujeto experimenta dicha especie de viaje fuera de sí mismo como cuerpo astral; un viaje, por cierto, parecido, en cierto modo, al que abandona el cuerpo físico en el momento de la muerte (Rubia 2015: 38).

Afirma Adile en este verso: «El pájaro del corazón está volando para observar el mundo» (1890: 213).

La poesía de los amigos de Dios es como una interpretación del Corán. Su lenguaje corporal y su lenguaje verbal están inspirados por Dios, porque, como dice el Profeta, el corazón de los creyentes está entre las dos manos de Él, haciéndolo girar como quiere. Pero, al contrario, la poesía de los poetas es sólo sueño. La intención de los poetas es expresar su personalidad. Estos poetas piensan que la poesía de los amigos de Dios es igual a la del resto de poetas. Pero no saben que los poemas místicos están inspirados por Dios. Porque los poemas de los místicos no pretenden expresar sus propias personalidades sino mostrar a Dios. En general la poesía sufí, es de carácter simbólico, y no siempre es fácil acceder a su significación espiritual. El éxtasis consiste en alcanzar un estado interior más allá de lo creado e, incluso, más allá del propio ser. Afirma la teóloga inglesa Margareta Smith: «In the spiritual life there could be neither male nor female». Y da ejemplo de Attâr a quién Adile mencionaba en sus poemas:

The Sufis, are, they have no separate existence in the Unity of God. In the Unity, what remains of the existence of "I" or "thou"? So how can "man" or "woman" continue to be? So too, Abu 'Ali FarmadhI said, "Prophecy is the essence, the very being, of power and 
sublimity. Superiority and inferiority do not exist in it. Undoubtedly saintship is of the same type. (Smith 1928: 2)

Este dicho del Profeta confirma la igualdad entre género en mundo del islam:

If any of the male companions or female disciples be buried in a holy place, they will intercede for such dwellers in that place as are worthy of their intercession. (Smith 1928:2)

Todos los santuarios de mujeres santas han sido venerados por musulmanes, en algunos casos durante siglos pasados, y siguen siendo objeto de veneración hoy en día. Se celebran festivales en los santuarios de mujeres santas, y estos santuarios forman parte hoy en día del islam popular. En el islam moderno, la mujer incluso más que el hombre, está superando el islam ortodoxo.

\section{UNA PERSONALIDAD INDEPENDIENTE ENTRE EL DOLOR Y EL ÉXTASIS MÍSTICO}

Escribe Adile acerca del éxtasis lo que vivió:

En todos los lados está la tranquilidad y el amante esta en éxtasis por Su luz [...]

Entra el éxtasis del amor para aguantar este dolor

Adile, esto es un país superior, allí vas a encontrar la felicidad [...]. (1890: 20)

En la historia del sufismo, se pueden ver ejemplos de cómo ciertas prácticas sufíes han sido aplicadas como una especie de terapéutica sobre el individuo. El citado Louis Massignon (1883-1962) afirma lo siguiente al respecto:

Le soufisme peut etre envisage aussi comme une thérapeutique mentale. La maitre l'expérimente d'abord sur soi-même, a fin de communiquer aux autres, par son enseignement et par sa pratique, une médecine éprouvée, qui est sa voie. En développant sa vie intérieure et en guidant ses disciples vers leur propre développement, le maitre enseigne, on le verra, a guérir la douleur des cœurs et a panser les plaies d'une communauté déchirée pas les vices de membres indignes. (Chevalier 1974: 1)

El sufismo, acepta el desconsuelo de la lejanía de Dios y el dolor interior que ello produce como una realidad que sobrepasa el umbral de la sensibilidad normal. Procesa este pesar interior y lo utiliza para alcanzar un nivel espiritual superior de perfeccionamiento espiritual como afirma Adile en su verso anterior. Y en esta práctica de escribir poemas va más allá de sí misma.

Ralph W. Hood, profesor de psicología de la Universidad de Tennessee, caracteriza la experiencia mística diciendo que el yo reflexivo es sustituido por otro tipo de yo, al que llama yo transcendente. Mientras que el yo reflexivo se caracteriza por la unidad de la persona, en el yo trascendente la unidad es de naturaleza completamente diferente, ya que tal unidad lo es con una realidad 
trascendente fuera del sujeto. Como se puede leer en el verso de Attâr: «El amante cuando entra en éxtasis, su corazón se llena con fuego» (Smith 1928: 183) esto es lo que afirma el sabio y poeta sufí persa Feriduddin Attâr, una de las principales fuentes espirituales y literarias de las que bebió Adile: «¿Qué es el éxtasis? Es volverse dichoso gracias a la verdadera mañana, volverse fuego sin la presencia del sol» (Schimmel 2002: 196).

Se suele decir que, para realizar la unidad con lo absoluto, lo divino, hay que superar las limitaciones de nuestro ego. Hay que trascender el yo para llegar a lo que se ha llamado en la terminología budista nirvana, o vecd en la terminología sufí (Rubia 2015: 33). Según el filósofo francés Jean Chevalier, el dolor experimentado en el camino espiritual ayuda a la hora del desplazamiento del propio yo. En realidad, es la focalización del ser en lo divino lo que hace generoso al sufrimiento. Desde el sufismo no se entiende el dolor como una ascética mortificadora. Aquí se habla de la aceptación positiva del dolor y de la grandeza que éste encierra. En una palabra, aquí se habla del sacrifico. Para los derviches, el dolor interior constituye una manera de vivir, sabiendo que de lo que se trata es de transformarlo en una alegría radical e incomparable a todo placer. Como afirma Adile: «Dolor es placer, separación es gratitud / Su capricho es un regalo, Su crueldad es una belleza» (1890: 215).

Hay que tener bien presente que los derviches miran al dolor en forma positiva, como si se tratara de una luz proveniente de Dios. Por eso, precisamente, lo reciben con valentía e incluso con alegría como Adile hizo en su vida. Adile Sultan tiene también una composición en Hicaz significa separación. En la música otomana representa el dolor.

\section{DEL AMOR HUMANO AL AMOR DIVINO}

Según los maestros del sufismo clásico, dicho amor divino puede manifestarse en varias etapas de la vida. Según el teólogo y académico turco Süleyman Derin, quien mejor explica la naturaleza de dicho amor es Gazali, conciliador del sufismo con la ortodoxia islámica, que dedicó largas meditaciones al estudio del amor en las distintas etapas de la vida del hombre:

The best definition of love that can be provided from a sufí perspective is that given by Gazali, who describes love as an inclination towards a thing, which gives pleasure. According to him, at the early stage, a child's love is directed exclusively towards the mother. As the child develops through the primary years of childhood, the child's love starts to explore different avenues. The love which was solely aimed at the mother in the beginning gradually inclines toward games, toys and expands further to include friends in its ambit. When the child reaches adolescence, he or she starts experiencing a natural inclination towards to opposite sex. Love of the opposite sex in the early stages of 
adulthood turns into the wealth and status at later ages. This process eventually culminates in the love of God. (Derin 2008: 15-16)

El poeta y filósofo Mevlâna Celâleddin Rumi (1207-1273) en sus propias palabras decía a sus alumnos: «¡Enamórate, enamórate! ¡Deja de ser un burro! Aunque seas un sultán, ¿hasta cuándo vas a seguir siendo un esclavo?». La experiencia del amor experimentada junto a su amigo y maestro Şems transformó radicalmente la vida y la personalidad de Rumi, quien dice así:

Mi corazón me coge y me lleva hacia el pueblo de mi amor. Me lleva donde bebí la copa de amor. Bebí tanto, me emborraché tanto, que mis zapatos y mi gorro han cambiado su lugar. (Bin Ahmed 2004: 55)

En la filosofía espiritual de los sufís nos encontramos que para alcanzar el más alto grado del amor divino hay que dejar atrás las etapas inferiores del temor y la esperanza. El hombre no es sino un siervo que le debe todo a su Señor. El mejor ejemplo de amor divino que ha dado la tradición sufí lo hallamos en la mística de Basora Râbi 'atü-l Adeviyye (752-801), introductora de dicha temática del amor divino entre los sufíes. El éxtasis místico de Râbia, su alto grado de intensidad, que tanto influyó en el discurso sufí, está en las antípodas del discurso racional de la filosofía. Su experiencia del amor divino se halla condensada en sus versos más conocidos, que tienen mucho de oración:

O My Lord! If I am worshipping you from fear of fire, burn me in the fires of hell; and if I am worshipping you from desire for Paradise, deny me Paradise. But if I am worshipping you for yourself alone, then do not deny me the sight of your magnanimous face. (Derin 2008: 92)

La estación final de la senda sufí es el amor a Dios o, si se quiere, la gnosis de Dios. De una u otra forma, todas las corrientes místicas reconocen estas dos metas: éxtasis amoroso y gnosis. El sufismo islámico no es una excepción, tal como reconoce la islamóloga alemana Annemarie Schimmel (1922-2003) (2007: 31). El órgano por excelencia de dichos amor y gnosis es el corazón, cuya capacidad de ver es patente para el espiritual sufí. Se trata del ojo del corazón. La imagen de dicho ojo auto-contemplativo es universal y puede hallarse tanto en Platón y Santa Teresa como en sufíes de la talla de Adile. A tal corazón inflamado que es el órgano de la visión mística lo denominan los sufíes ayne'l yakîn u ojo de la certeza. Por todo ello puede decirse que el místico no cree, sino que ve o, lo que es lo mismo, sabe por propia experiencia.

En el género divan quien sufre, quien espera, quien habla, quien echa de menos, quien espera siempre es amado, son los poetas. El amante nunca habla. Los amados (los poetas) hablan en lugar del amante. Escuchamos las palabras del amante a través de la poeta. El amante como un rey está arriba y ordena a veces 
con misericordia a veces con crueldad. El amante le viene a visitar pero para ganar su amor hay que trabajar mucho y empieza a usar un lenguaje rebelde aunque en seguida, como en el caso de Adile, se arrepiente y pide perdón. No le importa el deseo del amante si no sea lo que sea reclama que nunca dejará su amor y luchará por este amor:

Aunque voy a sufrir no me importa

Porque sacrifiqué mi vida a un sultán del amor muy importante. (1890: 99)

El amante, con sus labios rojos y pequeños, piel blanca, pelo negro como la noche, ojos negros como la noche, da la imagen de una mujer:

A veces por misterio está asombrada y a veces emborrachada y destruida

A veces es esclava de los labios de la guapa

$[\ldots]$

Corazón interpretó el color negro como el color de su pelo

¡Oh, amigo, que belleza es! En dos mundos no puedes imaginar tanta belleza. (1890: 109)

Cuando leemos este prototipo del amante en la poesía divan por los poetas hombres no suena raro. Pero si las poetisas utilizan el mismo lenguaje es distinto. En divan los poetas compiten con los personajes de las leyendas del amor como Majnun o Layla, para mostrar que son mejor amados que ellos. Aunque las mujeres poetas las comparaban con las amadas como Layla, Zulayha, Adile las compara con los amados como Majnun, Farjat como ocurre en sufismo más allá del género:

Mi corazón ha llenado con amor

Quien me hizo Majnun ¿no es el amor?

[...]

Mi corazón está volando para el sol eterno

Mi corazón está loco como Majnun

$[\ldots]$

Corazón quedó abandonado en una esquina de la separación

Por tu añoranza estoy como Majnun. (1890: 33)

En lenguaje técnico místico, desde el punto de vista literario, los poetas sufís dedican poemas enteros al vino, prohibido por el Corán pero celebrado por ellos a un nuevo nivel secreto. La palabra «emborracharse» en dos religiones tiene el mismo referente, en nuestro caso de Adile tan cercana al vocabulario teresiano:

A veces por el misterio esta asombrada y a veces emborrachada y destruida

$[\ldots]$

Estoy emborrachada como una mariposa ante la luz de la sabiduría

Ilumíname con Tu cara. Todo mi cuerpo está llorando ¡oh, ayuda, Dios!

$[\ldots]$ 
Le he visto con un vestido blanco dentro de luz

He perdido mi inteligencia, este corazón está emborrachado. (1890: 241)

Explica Santa Teresa de Jesús, el sentido místico bajo la metáfora de emborracharse:

Cuando está en este gozo tan embebecida y absorta, que no parece que está en sí, sino con una manera de borrachez divina que no sabe lo que quiere, ni qué dice, ni qué pide. En fin, no sabe de sí, más no está tan fuera de sí que no entiende algo de lo que pasa. (Janés 2015: 135)

En lenguaje místico sufí los colores como rojo, negro y blanco utiliza Adile no solo son visibles, como explica Victoria Cirlot, sino que también se oye, y ese sonido de color es el que hace vibrar el alma. Esa sinestesia de sentidos, la audición del color, corresponde a una percepción en la que no solo actúan los sentidos exteriores, sino que también intervienen los interiores convirtiendo la percepción en experiencia interior (Cirlot 2019: 76). Los colores para los poetas sufís como Adile son seres vivos:

De repente el ambiente se volvió el día del juicio

Cayó sangre de arbusto de color rojo. (1890: 82)

\section{UNA POETA DE LOS POBRES Y HUÉRFANOS}

En su casa de la costa del Bósforo, Adile Sultan se reunía frecuentemente con los maestros espirituales e intelectuales de su época. Su casa fue una especie de refugio para los pobres y los huérfanos.

Dio especial importancia a la educación de las mujeres. Como en su vida, en sus poemas utiliza un lenguaje sencillo, profundo y emocional. Perder a su madre tan pronto la hizo muy sensible y volcó su interés en la literatura y especialmente en la poesía.

En los archivos de la biblioteca de obras antiguas de la Universidad de Estambul encontramos la herencia de Adile Sultán dividida entre sus 18 fundaciones dedicadas a los necesitados. La herencia incluye inmuebles, dinero en efectivo, fuentes construidas en la ciudad, escuelas, pozos, tumbas.

En 1868, por primera vez el sultán decidió premiar a una mujer y otorgó el «Premio de la misericordia» a Adile Sultan.

Adile Sultan entró en la orden sufí de Naqshbandi y se dedicó a actividades de caridad. Fue discípula, del shayj sufí 'Alî Efendi de esta misma orden. Invirtió su patrimonio en la construcción de un total de catorce fundaciones benéficas de ayuda a los más desfavorecidos. En su divan poético no solo escribió poemas dedicados a su maestro, sino que, al mismo tiempo, compuso doce poemas para 
otros tantos maestros diferentes. Respecto a su estilo literario, que era una poesía llamada ladun, es decir, inspirada espiritualmente por lo divino, justo como la de los grandes poetas y místicos turcos otomanos Shayjh Gâlib Dede (1757-1799) y Fuzuli (1483-1556). En el palacio, Adile Sultan convocaba, frecuentemente, reuniones literarias con las mujeres y hombres «mezclados» que acababan siempre con música espiritual.

Adile Sultan tenía una casa de verano en Validebağ y un palacio famoso en Kandilli. Ella dejó su palacio en Kandilli tras la muerte de su marido y se trasladó al palacio costero en Findıklı. Donó este palacio al estado con la condición de que se convirtiera en la primera escuela secundaria para niñas en el Imperio Otomano. Su deseo se cumplió sólo en 1916 (debido a las guerras), cuando el Turco joven activista, estadista y educador Ahmed Riza abrió la Adile Sultan Mektebi Sultanisi (Adile Sultan Imperial Girls School), hoy conocido como Kandilli Anatolia Alto, la escuela para chicas, aunque no se convirtió en la primera, pero si en la segunda escuela secundaria para niñas en el imperio.

Adile Sultan murió en 12 de febrero de 1899 en el Palacio de Costas. Fue enterrada en el mausoleo de su marido e hijos, en el barrio Eyüp, en Estambul.

En diario Ikdam de la época anunció su muerte con un poema:

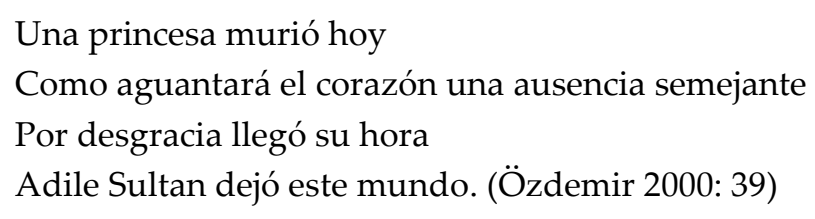

Sus poemas emanados de sus experimentos personales a partir de la «Alabanza de Dios» hay que inscribirlos dentro de una tradición masculina cuyo modelo se encuentra en la literatura mística otomana. Pero aunque no se haya conservado ningún otro escrito femenino de este tipo, es probable que otras místicas otomanas hubieran escrito sus meditaciones también.

Hasta mediados del siglo XIX la literatura culta escrita en turco había sido, predominantemente, la poesía del divan, de influencia persa dentro de la literatura islámica.

Adile Sultan escribe en estilo gazal, que es una forma poética de la literatura persa, turca y árabe. En la literatura turca esta forma se utiliza en la literatura de divan. Está formada por dos coplas a quince coplas. Su tema principal es el amor, el dolor, muerte de su marido, de sus hijos, de su padre, de sus hermanos, sobre los maestros clásicos de la historia del sufismo, sobre los doce imames del mundo islam, sobre los cuatro califas, sobre Dios, sobre Mumammad, sobre la noche de la ascensión del Profeta a los cielos. 
El Divan de Adile Sultan tiene cinco copias en tres diferentes bibliotecas de Estambul: una en la Biblioteca de Ali Emiri, otra en la biblioteca de la Universidad de Estambul y otras tres en la biblioteca del Museo del Palacio Topkapı.

\section{CONCLUSIÓN}

Como pasaba con otros místicos sufís como Rumi y Rabiatul Adeviyya, escribir para Adile Sultan era simplemente copiar, copiar lo que está escrito en el corazón.

La poesía de Adile refleja las diferentes etapas de la mística, lujo, perdidas, soledad en este mundo e incertidumbre, hasta el momento en que está tranquila ser esclava de un sheikh: «Como un regalo, esta pobre es una de sus esclavas» (1890: 59). En otros versos dice también: Para los seguidores del camino Él es una luz / Olvida mis rebeldías, hazme esclava del maestro» (1890: 61). Cree firmemente en el poder de los amigos de Dios, pero sabe también que el maestro sólo es un intermediario que prepara a los discípulos para la unión;

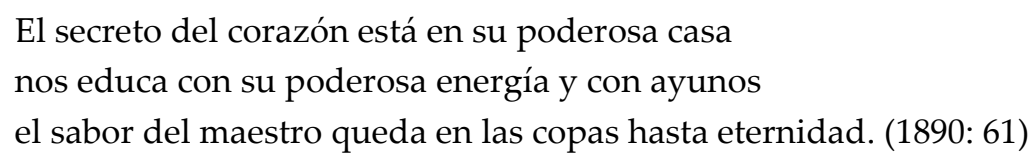

El secreto del corazón está en su poderosa casa nos educa con su poderosa energía y con ayunos

el sabor del maestro queda en las copas hasta eternidad. (1890: 61)

O puede identificarse con todos los maestros espirituales, con todos los amantes de Dios: «Estoy enamorada / Quién me hizo Majnun, ¿no es el amor?» (1890: 33) o «Llega un tiempo en el que yo, Adile, como Majnun, estoy cruzando las montañas» (1890: 231).

Estos poemas son, idénticos a la poseía sufí anterior escrita no solo en otomano sino en las lenguas más diversas.

El uso de las metáforas similares para describir la condición de separación del amado divino y la salida de las amadas en su búsqueda es una de las características comunes entre los versos de la literatura mística islámica y cristiana, observando cómo cada uno de los textos describe poética y teológicamente la condición del amor espiritual en separación, a pesar de las diferencias que guardan entre sí.

Los poemas de Adile afirman que los versos son el escenario donde se manifiesta el gran espectáculo de las emociones espirituales, que parte de una perspectiva amplia de la cultura y la práctica religiosa, donde la poesía no es una disciplina separada del resto de la comunicación con Dios, tal como se concibe en la cultura islámica en el ámbito religioso y cultural turco. El mismo que ha sufrido en las últimas décadas importantes cambios, provocados en gran medida por las transformaciones sociales asociadas a la modernización tecnológica y la configuración de un mundo global. En estas circunstancias la mayor difusión de algunas prácticas tradicionales y religiosas no siempre ha sido bien comprendida 
en sus profundos alcances espirituales. Quizás por esa razón el Divan de Adile Sultan no está traducido a los otros idiomas. Y aquí hemos llegado al punto, según la afirmación de Alois M. Haas:

La poesía no es lo que nuclearmente pueda definirse por su carácter en tanto que obra, esto es, por el conglomerado de signos e imágenes que fluyen en ella, sino por su apertura, intensificada lingüísticamente, en paralelismos, a su propio conjunto de sucesos y acontecimientos. Pero, este conjunto, que deriva del carácter insondable del sujeto y de su estructura misteriosa, es él mismo enigmáticamente impenetrable, y aunque interprete, jamás puede abrirse de tal modo que con ello quede volatilizado el misterio. (Haas 1990: 70)

* El artículo forma parte de la investigación postdoctorado Biblioteca Haas 2019 de la universidad de Pompeu Fabra realizada bajo la dirección de la Dra. Victoria Cirlot.

\section{BIBLIOGRAFÍA}

SultaN, A. (1890), Divan, İstanbul, Matbaa-i Osmaniye. (traducción al castellano no publicada por Nesrin Karavar)

BIN AHMED, F. (2004), Sipehsalar Risalesi, Hz. Mevlâna ve Yakınları, İstanbul, Elest.

CERVANTES, E. (1893), «Education and Literature of the Women of Turkey», Internet Archive. Disponible en <https://archive.org/details/addressoneducati00cerv /mode/2up >.

CIRLOT, V. (2019), Visión en rojo, Madrid, Siruela.

Chevalier, J. (1974), Le Soufisme. Ou L'ivresse de Dieu Dans La Tradition de L'islam, Paris, Celt.

CORBIN, H. (2000), El Hombre de Luz, en el sufismo iranio, Madrid, Siruela.

DERIN, S. (2008), Love in Sufism, From Rabia to Ibn al-Farid, İstanbul, İnsan.

GARNETT, L. J. M. (2009), Türkiye'nin Kadınları ve Folklorik Özellikleri, (Çev. Nurettin Elhüseyni), İstanbul, Oğlak Yay.

Göle, N. (1991), Musulmanas y modernas. Velo y civilización en Turquía, Madrid, Talasa.

HAAS, A. M. (1999), Visión en azul. Estudios de mística europea, Madrid, Siruela. (Selección de textos. Cirlot, V. y Vega, A.).

JANES, C. (selección y presentación) (2015), Santa Teresa de Jesús. Poesía y pensamiento (Antología), Madrid, Alianza.

Maíllo SAlGADO, F. (1999), Vocabulario de historia árabe e islámica, Madrid, Akal.

MAZHARI, A. (2014), «Los Siete Valles del Amor de 'Attar», Sufi, 28, Madrid, 15.

ÖzDEMIR, H. (2000), Adile Sultan Divanı, Ankara, T. C. Kültür Bakanlığı.

RuBIA, F. J. (2015), El Cerebro Espiritual, Barcelona, Fragmenta.

SCHIMMEL, A. (2007), Introducción al Sufismo, Barcelona, Kairos.

SMITH, M. (1928), Rabi'a The Mystic and Her Fellow-Saints in Islam, Cambridge, Cambridge University. 
ŞEBÜSTERI, M. (2011), Gülşen-i Raz, İstanbul, Türkiye İș Bankası.

UludAG̣, S., (2004), İslam Açısından Musiki ve Sema, İstanbul, Kabalcı.

Williams, J. (1901-1902), The Varieties of Religious Experience. A Study in Human Nature, Edinburgh, The Modern Library.

ZEYNEP H. (1913), A Turkish Woman's European Impressions, Cambridge, Cambridge University. 